Article

\title{
Remote Sensing of Sonoran Desert Vegetation Structure and Phenology with Ground-Based LiDAR
}

\author{
Joel B. Sankey ${ }^{1, *}$, Seth M. Munson ${ }^{2}$, Robert H. Webb ${ }^{3}$, Cynthia S. A. Wallace ${ }^{4}$ \\ and Cesar M. Duran 5
}

1 U.S. Geological Survey, Southwest Biological Science Center, Grand Canyon Monitoring and Research Center, 2255 N. Gemini Dr., Building \#4, Flagstaff, AZ 86001, USA

2 U.S. Geological Survey, Southwest Biological Science Center, P.O. Box 5614, Building 56, Suite 150, Flagstaff, AZ 86011, USA; E-Mail: smunson@usgs.gov

3 School of Natural Resources, University of Arizona, 6710 W. El Camino del Cerro, Tucson, AZ 85745, USA; E-Mail: rhwebb@email.arizona.edu

4 U.S. Geological Survey, Western Geographic Science Center, 520 N Park Ave., \#111, Tucson, AZ 85719, USA; E-Mail: cwallace@usgs.gov

5 School of Geography and Development, University of Arizona, P.O. Box 210076, Tucson, AZ 85721, USA; E-Mail: mdurans@email.arizona.edu

* Author to whom correspondence should be addressed; E-Mail: jsankey@usgs.gov; Tel.: +1-928-556-7289; Fax: +1-928-556-7092.

Academic Editors: Arnon Karnieli and Prasad S. Thenkabail

Received: 29 May 2014 / Accepted: 2 December 2014 / Published: 30 December 2014

\begin{abstract}
Long-term vegetation monitoring efforts have become increasingly important for understanding ecosystem response to global change. Many traditional methods for monitoring can be infrequent and limited in scope. Ground-based LiDAR is one remote sensing method that offers a clear advancement to monitor vegetation dynamics at high spatial and temporal resolution. We determined the effectiveness of LiDAR to detect intra-annual variability in vegetation structure at a long-term Sonoran Desert monitoring plot dominated by cacti, deciduous and evergreen shrubs. Monthly repeat LiDAR scans of perennial plant canopies over the course of one year had high precision. LiDAR measurements of canopy height and area were accurate with respect to total station survey measurements of individual plants. We found an increase in the number of LiDAR vegetation returns following the wet North American Monsoon season. This intra-annual variability in vegetation structure detected by LiDAR was attributable to a drought deciduous
\end{abstract}


shrub Ambrosia deltoidea, whereas the evergreen shrub Larrea tridentata and cactus Opuntia engelmannii had low variability. Benefits of using LiDAR over traditional methods to census desert plants are more rapid, consistent, and cost-effective data acquisition in a high-resolution, 3-dimensional context. We conclude that repeat LiDAR measurements can be an effective method for documenting ecosystem response to desert climatology and drought over short time intervals and at detailed-local spatial scale.

Keywords: Lidar; ground-based Lidar; terrestrial laser scanning (TLS); creosote; prickly pear; triangle-leaf bursage; drought; global change; monitoring

\section{Introduction}

Long-term vegetation monitoring efforts have become increasingly important for understanding ecosystem response to climate, rising $\mathrm{CO}_{2}$, and natural and anthropogenic disturbances [1-4]. Although plant ecologists have traditionally monitored vegetation by revisiting permanent plots or transects and assigning values of plant abundance with visual estimates, mapping, or line-intercept measurements $[5,6]$, these efforts can be costly, time-intensive, limited in scope, infrequent, sometimes subjectively biased and poorly replicated across large areas. Moreover, investigators traversing these plots while making measurements may compact soils, trample seedlings, and damage established vegetation. Therefore, new approaches that non-invasively and rapidly measure vegetation monitoring plots may help to maintain the integrity, increase measurement frequency, and improve the continuity of permanent plots $[7,8]$.

Ground- and airborne-based remote sensing approaches can significantly improve upon the limitations of traditional vegetation monitoring methods by increasing the temporal and spatial resolution of measurements with less effort and cost. Light-detection and ranging (LiDAR) from a ground-based platform is one remote sensing method that offers a clear advancement to track vegetation dynamics at high spatial and temporal resolution $[9,10]$. LiDAR provides spatially-explicit three-dimensional (3-D) characterization of vegetation structure, permitting high precision estimates of plant canopy height, area, and density [11-15]. Obtaining high-resolution 3-D vegetation structural information with LiDAR provides additional benefits of estimating plant biomass and carbon storage [11,16,17], leaf-area index [18-20], and biophysical processes and interactions [21,22]. Ground-based LiDAR (henceforth simply referred to as LiDAR) may be particularly useful where it is preferable to rapidly sample plots in consistent high resolution, while avoiding physical disturbance to the study area [8]. While some commercial LiDAR systems might be prohibitively expensive for some monitoring efforts, low cost systems also exist [23].

Due to the constraints of traditional vegetation monitoring, many studies focus on inter-annual to decadal trends of vegetation abundance and structure. One of the longest-running vegetation monitoring sites in the world occurs in the Sonoran Desert, where plots have been re-measured approximately every 10 years since 1906 [4]. The relatively long vegetation sampling intervals at this site and others in the region does not match the strong seasonal and pulsed patterns of precipitation in the Sonoran Desert [24], in addition to other short-term climate and disturbance factors that can elicit vegetation responses at 
a shorter time scale $[25,26]$. Furthermore, traditional vegetation monitoring typically does not capture phenological developments in the life-cycles of plants, such as leaf-out and leaf-drop exhibited by deciduous shrubs in the Sonoran Desert [25,27]. Capturing the photosynthetically active periods of plants by intensively monitoring changes in their foliar canopies is essential for understanding productivity and associated ecosystem dynamics of the site. In this paper, we examine whether ground-based LiDAR provides a means to track intra-annual, fine-scale variability of vegetation structure and phenology, which can improve upon the limitations of traditional vegetation monitoring. We chose to use plot 4 at the Desert Laboratory, Tucson, Arizona, which has been measured irregularly since 1906 (Tables 1 and 2) [28].

Table 1. History of measurements of cover of perennial vegetation on plot 4 at the Desert Laboratory in Tucson, Arizona.

\begin{tabular}{cccccccc}
\hline Year & $\mathbf{1 9 0 6}$ & $\mathbf{1 9 6 8}$ & $\mathbf{1 9 7 8}$ & $\mathbf{1 9 8 5}$ & $\mathbf{2 0 0 1}$ & $\mathbf{2 0 1 0}$ & $\mathbf{2 0 1 2}$ \\
\hline Species & & \multicolumn{7}{c}{ Cover $\mathbf{( \% )}$} \\
\hline Acacia constricta & $\mathrm{Nm}{ }^{*}$ & 1.26 & 1.17 & 1.59 & 1.30 & 1.43 & 1.63 \\
Acacia greggii & $\mathrm{Nm}$ & 0.00 & 0.57 & 0.78 & 0.00 & 0.00 & 0.00 \\
Ambrosia deltoidea & $\mathrm{Nm}$ & 29.47 & 23.43 & 35.08 & 24.99 & 8.49 & 11.85 \\
Carnegiea gigantean & $\mathrm{Nm}$ & 0.08 & 0.04 & 0.07 & 0.19 & 0.13 & 0.16 \\
Cylindropuntia fulgida & $\mathrm{Nm}$ & 0.00 & 0.00 & 0.00 & 0.59 & 1.17 & 0.94 \\
Cylindropuntia leptocaulis & $\mathrm{Nm}$ & 0.54 & 0.74 & 1.12 & 0.00 & 0.17 & 0.25 \\
Cylindropuntia versicolor & $\mathrm{Nm}$ & 0.00 & 0.09 & 0.22 & 0.70 & 1.61 & 1.85 \\
Dyssodia pentachaeta & $\mathrm{Nm}$ & 0.19 & 0.00 & 0.00 & 0.00 & 0.00 & 0.00 \\
Echinocereus fasciculatus & $\mathrm{Nm}$ & 0.00 & 0.00 & 0.02 & 0.00 & 0.02 & 0.03 \\
Ferocactus wizlizenii & $\mathrm{Nm}$ & 0.00 & 0.00 & 0.00 & 0.00 & 0.02 & 0.03 \\
Isocoma tenuisectus & $\mathrm{Nm}$ & 0.00 & 0.00 & 0.01 & 0.00 & 0.00 & 0.00 \\
Krameria grayi & $\mathrm{Nm}$ & 0.00 & 0.00 & 0.00 & 0.14 & 0.06 & 0.06 \\
Larrea tridentata & $\mathrm{Nm}$ & 3.62 & 2.46 & 4.17 & 8.09 & 8.81 & 9.07 \\
Mammillaria grahamii & $\mathrm{Nm}$ & 0.00 & 0.00 & 0.01 & 0.00 & 0.00 & 0.00 \\
Muhlenbergia porter & $\mathrm{Nm}$ & 0.16 & 0.03 & 0.00 & 0.00 & 0.00 & 0.00 \\
Opuntia engelmannii & $\mathrm{Nm}$ & 0.00 & 1.50 & 3.53 & 0.55 & 2.30 & 2.83 \\
Psilostrophe cooperi & $\mathrm{Nm}$ & 1.17 & 0.01 & 0.00 & 0.00 & 0.00 & 0.00 \\
Tiqulia canescens & $\mathrm{Nm}$ & 0.00 & 0.00 & 0.00 & 0.00 & 0.00 & 0.00 \\
Unknown & $\mathrm{Nm}$ & 0.00 & 0.03 & 0.00 & 0.00 & 0.00 & 0.00 \\
Zinna pumila & $\mathrm{Nm}$ & 0.09 & 0.00 & 0.00 & 0.00 & 0.00 & 0.00 \\
Totals & & 36.58 & 30.07 & 46.60 & 36.55 & 24.21 & 28.70 \\
\hline & & & Not measured. & & & &
\end{tabular}

\section{Objectives}

Our objective was to investigate the potential for ground-based LiDAR to detect monthly variability in vegetation structure during the course of one year at a long-term monitoring plot in a Sonoran Desert plant community composed of cacti, deciduous and evergreen shrubs (Figure 1a). We focused on individual plants aggregated by species within a monitoring plot, but also considered the scale of all perennial vegetation within the plot. To meet our objective, we determined whether LiDAR height and canopy measurements were accurate relative to a recently mapped (surveyed) census of perennial plants, 
and evaluated whether accuracy increased when LiDAR measurements were determined from a single, relative to multiple, scan positions. We compared changes in canopy height, canopy area, and the percent of returns from vegetation detected with LiDAR to monthly precipitation and satellite-derived vegetation greenness. The purpose of these comparisons was to determine whether plant phenology and structure observed in a small area with LiDAR was related to water availability and the condition of vegetation over a greater spatial extent.

Table 2. History of measurements of density of perennial vegetation on plot 4 at the Desert Laboratory in Tucson, Arizona.

\begin{tabular}{|c|c|c|c|c|c|c|c|}
\hline Year & 1906 & 1968 & 1978 & 1985 & 2001 & 2010 & 2012 \\
\hline Species & \multicolumn{7}{|c|}{ Density (Individuals/ha) } \\
\hline Acacia constricta & 609 & 406 & 406 & 406 & 203 & 101 & 101 \\
\hline Acacia greggii & 0 & 0 & 101 & 101 & 0 & 0 & 0 \\
\hline Ambrosia deltoidea & 0 & 25,761 & 24,848 & 24,341 & 20,588 & 12,475 & 12,373 \\
\hline Carnegiea gigantean & 101 & 101 & 101 & 101 & 203 & 203 & 203 \\
\hline Cylindropuntia fulgida & 203 & 0 & 0 & 0 & 101 & 0 & 101 \\
\hline Cylindropuntia leptocaulis & 0 & 203 & 609 & 811 & 406 & 0 & 203 \\
\hline Cylindropuntia versicolor & 0 & 0 & 101 & 101 & 203 & 304 & 203 \\
\hline Dyssodia pentachaeta & 0 & 3043 & 0 & 0 & 0 & 0 & 0 \\
\hline Echinocereus fasciculatus & 406 & 0 & 101 & 609 & 0 & 101 & 101 \\
\hline Ferocactus wizlizenii & 0 & 0 & 0 & 0 & 0 & 101 & 101 \\
\hline Isocoma tenuisectus & 203 & 0 & 0 & 203 & 0 & 0 & 0 \\
\hline Krameria grayi & 0 & 0 & 0 & 0 & 203 & 406 & 406 \\
\hline Larrea tridentata & 101 & 203 & 710 & 507 & 913 & 1116 & 1116 \\
\hline Mammillaria grahamii & 0 & 0 & 101 & 101 & 1217 & 101 & 203 \\
\hline Muhlenbergia porter & 0 & 101 & 203 & 0 & 0 & 0 & 0 \\
\hline Opuntia engelmannii & 0 & 101 & 406 & 406 & 406 & 304 & 304 \\
\hline Psilostrophe cooperi & 3144 & 5274 & 101 & 0 & 0 & 0 & 0 \\
\hline Tiqulia canescens & 0 & 0 & 0 & 0 & 0 & 101 & 0 \\
\hline Unknown & 101 & 0 & 101 & 0 & 0 & 0 & 0 \\
\hline Zinna pumila & 0 & 406 & 0 & 0 & 0 & 0 & 0 \\
\hline Totals & 4868 & 35,598 & 27,890 & 27,687 & 24,442 & 15,314 & 15,415 \\
\hline
\end{tabular}

\section{Methods}

\subsection{Study Site}

Perennial plants have been censused in eighteen permanently-marked $10 \mathrm{~m} \times 10 \mathrm{~m}$ plots at the Desert Laboratory in Tucson, Arizona $\left(32^{\circ} 13^{\prime} \mathrm{N}, 111^{\circ} 00^{\prime} \mathrm{W}\right)$ at various times since 1906 [29,30]. The Desert Laboratory receives biseasonal precipitation, split nearly equally between the summer and winter months, and it has a mean annual precipitation of $298 \mathrm{~mm}$. Plot 4, the plot analyzed in this study, is located on an alluvial plain on the west side of the Desert Laboratory at an elevation of $727 \mathrm{~m}$ and has an area of $98.2 \mathrm{~m}^{2}$. This plot is relatively level, has a gravelly sandy loam soil, and has a plant community dominated by Ambrosia deltoidea (triangle-leaf bursage), Larrea tridentata (creosote bush), and various cacti, including Opuntia engelmannii (pricklypear) (Table 3 and Figure 1). Since 1968, species cover on 
the plot has ranged between: $<10 \%-30 \%$ for Ambrosia deltoidea, 2\%-9\% for Larrea tridentata, and 0\%-3\% for Opuntia engelmannii (Table 1). Larrea tridentata are taller shrubs on the plot with average height of $\sim 1 \mathrm{~m}$, whereas Ambrosia deltoidea and Opuntia engelmannii are smaller-statured with average height closer to a half-meter (Table 3).

The plant community at plot 4 is typical of the Arizona Upland subdivision of the Sonoran Desert [31]. Ambrosia deltoidea is a drought-deciduous shrub, whereas Larrea tridentata is an evergreen shrub and the cacti are primarily stem photosynthetic. Due to these differences in the photosynthetic strategy of our focal plant species, we expected to detect high intra-annual variability in vegetation structure attributable to seasonal leaf growth of Ambrosia with low intra-annual variability (i.e., small changes in growth) of Larrea and cacti.
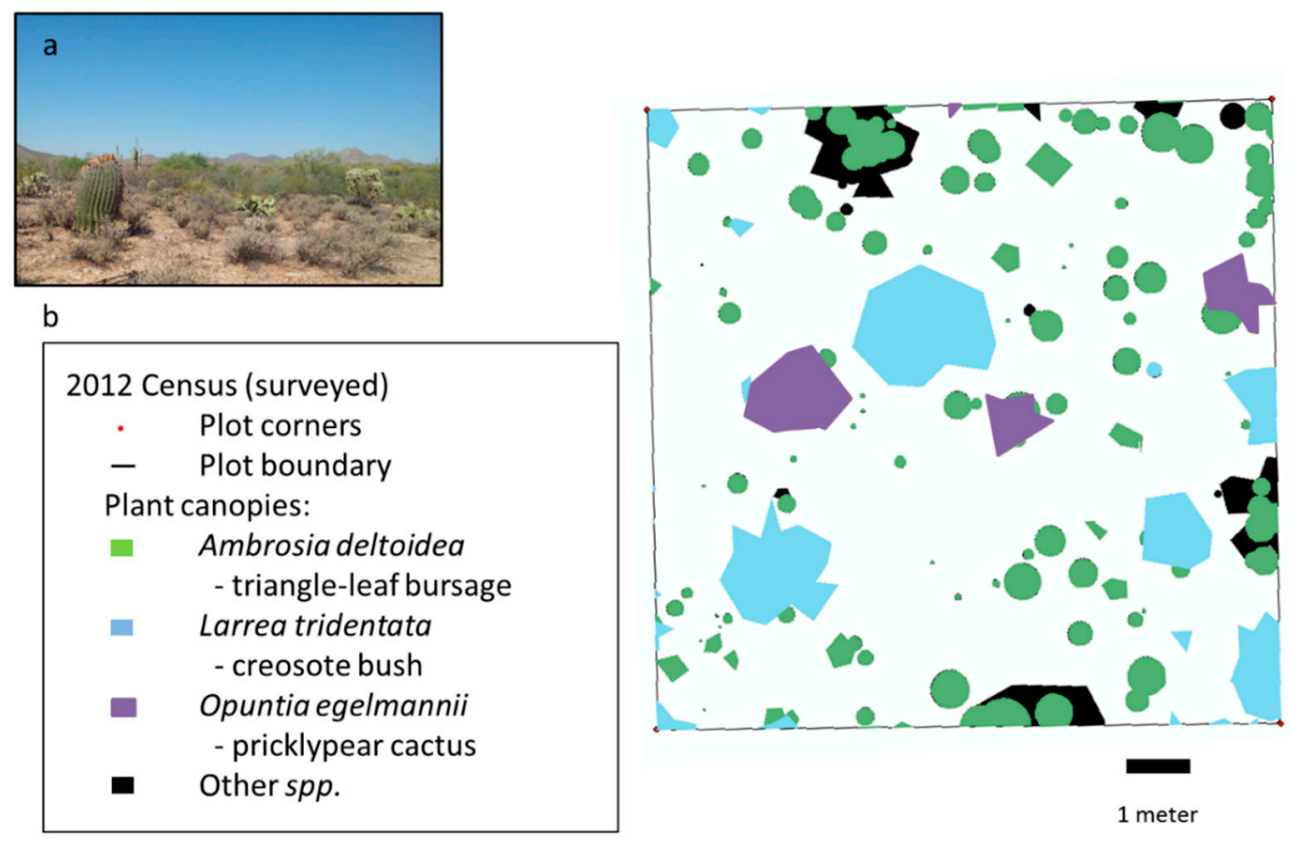

Figure 1. (a) photo of vegetation in the study area; and (b) map of surveyed plant canopies from the 2012 census of plot 4 at the Desert Laboratory in the Sonoran Desert; Individual plants of the three dominant species are identified in (b).

Table 3. Canopy height and area by predominant species on plot 4 at the Desert Laboratory in Tucson, Arizona measured by total station survey (April 2012).

\begin{tabular}{cccccc}
\hline \multirow{2}{*}{ Species } & \multirow{2}{*}{$\boldsymbol{N}$} & \multicolumn{2}{c}{ Canopy Height $(\mathbf{m})$} & \multicolumn{2}{c}{ Canopy Area $\left(\mathbf{m}^{\mathbf{2}}\right)$} \\
\cline { 3 - 6 } & & Mean & SE & Mean & SE \\
\hline Ambrosia deltoidea & 25 & 0.40 & 0.02 & 0.14 & 0.02 \\
Larrea tridentata & 15 & 1.07 & 0.12 & 0.8 & 0.23 \\
Opuntia engelmannii & 4 & 0.61 & 0.06 & 0.74 & 0.29 \\
Cylindropuntia leptocaulis & 2 & 0.78 & 0.26 & 0.24 & 0.16 \\
Cylindropuntia versicolor & 2 & 1.8 & $--{ }^{*}$ & 1.48 & 0.79 \\
Acacia constricta & 1 & 1.70 & -- & 2.07 & -- \\
Krameria grayi & 1 & 0.20 & -- & 0.04 & -- \\
Cylindropuntia fulgida & 1 & 2.35 & -- & 1.47 & - \\
Total & 51 & 0.70 & 0.07 & 0.50 & 0.10 \\
\hline
\end{tabular}

* height not recorded for 1 individual. 


\subsection{Census}

Different methods have been used to census perennial plants growing inside plot 4 since 1906 [29,30]. However starting in 2001, a total station was used in combination with a reflector prism mounted on a stadia rod to record the position of the center of the stems and the size and height of the canopies. While the accuracy of each surveyed point is on the order of millimeters, the accuracy of the survey data is likely on the order two to four centimeters owing to the footprint (diameter) of the stadia rod. During the 2012 census, which was used as the baseline for comparison with LiDAR data collected for this study, points were captured with the total station for the canopy perimeter of all live plants (Figure 1b). The height of all plants was measured as the length between the root crown and the top of the tallest live vegetative branch. It takes approximately $6-8 \mathrm{~h}$ to census the plot using the rod and total station survey method.

\subsection{LiDAR Data Collection}

We completed approximately monthly LiDAR scans of plot 4 from March 2011-May 2012 (Table 4). Data were collected with an OPTECH ILRIS 3D LiDAR unit mounted on a tripod from a single scan position elevated $3.35 \mathrm{~m}$ above ground. The tripod was centered on a permanent survey marker (rebar) installed outside of the study plot, and the farthest scan point within the plot was less than $15 \mathrm{~m}$ from the instrument. The instrument employs a pulsed infrared $(1535 \mathrm{~nm})$ laser with a beam divergence of $0.00974^{\circ}$ and beam diameter of $14 \mathrm{~mm}$ at a range of $50 \mathrm{~m}$. Distance accuracy is quoted at $7 \mathrm{~mm}$ and positional accuracy at $8 \mathrm{~mm}$ at $100 \mathrm{~m}$ range. Data were collected with spot spacing of $15.00 \mathrm{~mm}$ at $50 \mathrm{~m}$ range. The instrument returned one data point per laser pulse. It took approximately $2 \mathrm{~h}$ to scan the plot from a single scan position.

Table 4. Root mean square error (RMSE) of LiDAR data registration to local coordinate system determined for each LiDAR data collection date.

\begin{tabular}{ccccc}
\hline \multirow{2}{*}{ Date } & \multicolumn{4}{c}{ RMSE (m) } \\
\cline { 2 - 5 } $\mathbf{X}$ & $\mathbf{Y}$ & $\mathbf{Z}$ & Total (Mean) \\
\hline 11 April 2011 & 0.004 & 0.009 & 0.013 & 0.009 \\
22 April 2011 & 0.007 & 0.008 & 0.013 & 0.010 \\
12 May 2011 & 0.014 & 0.012 & 0.027 & 0.018 \\
3 June 2011 & 0.007 & 0.011 & 0.008 & 0.009 \\
21 July 2011 & 0.008 & 0.010 & 0.004 & 0.007 \\
9 August 2011 & 0.014 & 0.014 & 0.008 & 0.012 \\
8 September 2011 & 0.006 & 0.008 & 0.009 & 0.008 \\
7 October 2011 & 0.020 & 0.005 & 0.011 & 0.012 \\
23 December 2011 & 0.006 & 0.009 & 0.020 & 0.012 \\
13 March 2012 & 0.017 & 0.009 & 0.019 & 0.015 \\
13 March 2012 * & 0.015 & 0.009 & 0.007 & 0.010 \\
11 May 2012 & 0.011 & 0.006 & 0.019 & 0.009 \\
\hline & * multiple (3) scan positions.
\end{tabular}




\subsection{LiDAR Processing}

For each collection date, initial processing of the LiDAR data was performed in OPTECH Polyworks software [32] to align scans and register each dataset to a common, local coordinate system based on a total station survey performed during the April 2012 census. Registration employed five control points marked with permanent survey markers, which included the four corners and the center of the plot. Spherical reflectors that were $73 \mathrm{~mm}$ diameter and coated with reflective paint were mounted on the permanent markers and used to identify the control points in the LiDAR data. The registration procedure was optimized by minimizing the root mean-square error of the control points for each LiDAR collection date. Scanning precision was evaluated by comparison of the radius of a sphere model fit to the point clouds for three individual reflectors from three data collection dates to the known radius of the reflectors.

After registration was completed in Polyworks, the datasets were processed in ENVI software version 4.8 (Exelis Visual Information Solutions, Boulder, CO, USA) using tools and metrics described in [33] to filter and classify low-elevation (ground) returns from higher-elevation returns likely to have reflected from the vegetation canopy. The same parameters for the filtering procedure were used to process the dataset from each collection date. The iterative procedure produced a point cloud dataset for each collection date with LiDAR points classified as either ground points or vegetation canopy (Figure 2). The point-cloud datasets were then processed to determine raster-based (2-cm cell resolution) metrics of: percent of returns from vegetation, percent of returns from ground surface, and mean ground and canopy height [34].

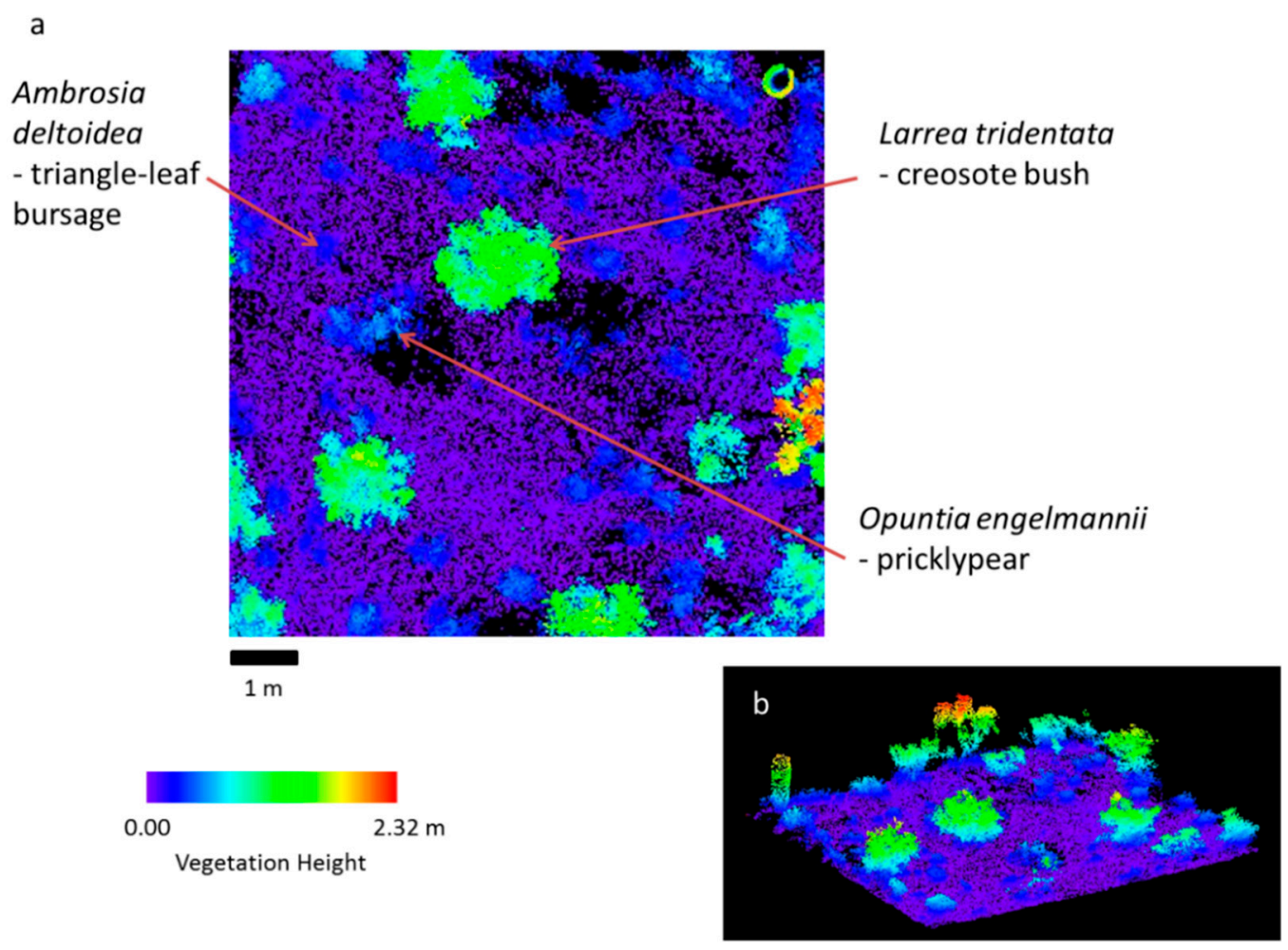

Figure 2. (a) plan and (b) profile views of a LiDAR point dataset classified by vegetation height for the $10 \mathrm{~m} \times 10 \mathrm{~m}$ study plot; Examples of individuals of the thrree dominant species are identified with arrows in (a). Black pixels within the study plot borders are locations of insufficient data to determine vegetation height. 
A GIS vector layer of the plot boundary produced from the total-station survey in April 2012 [30] was used to spatially constrain the LiDAR analysis to the study plot. The height-filtered LiDAR raster datasets of canopy height and percent of returns from vegetation were processed in GIS to produce vector layers that delineated individual canopies in the data for each collection date. In the total-station survey in April 2012, plant canopies of large individuals were mapped (Table 3). The area of these canopies identified in the total-station survey, were calculated for each LiDAR collection date. In the case of overlapping canopies where a smaller individual was contained partially or completely within a larger canopy, analysis focused on the individual with the larger canopy. Three species that were present at very low cover and density in 2012 were not included in our analysis of the LiDAR and survey data: Echinocereus fasciculatus (hedgehog cactus), Ferocactus wizlizenii (barrel cactus), and Carnegiea gigantean (saguaro cactus) (Table 3 ).

\subsection{LiDAR Measurement Accuracy and Analysis of Intra-Annual Variability}

The accuracies of LiDAR canopy height and area measurements were evaluated by comparing them to the total-station survey for one date of nearly coincident collections of the two types of data (LiDAR collected in March 2012 and total station survey conducted in April 2012). The potential limitation of scanning the plot from a single position was assessed for this LiDAR collection date by comparing LiDAR height and canopy measurements determined from a single scan position with measurements determined from a composite of LiDAR data collected from three scan positions (i.e., from 3 different sides of the plot, which took approximately 3 times as long to complete). In each comparison (i.e., single scan vs. three-scan LiDAR, single scan LiDAR vs. total station survey, or three-scan LiDAR vs. total station survey) a mean squared deviation (MSD) was calculated. The MSD was analyzed by components of standard bias (SB), non-unity (NU), and lack of correlation (LC), which were calculated with the following equations [35]:

$$
\begin{gathered}
S B \%=\frac{(\mu(\text { predicted })-\mu(\text { validation }))^{2}}{M S D} \\
N U \%=\frac{(1-b)^{2} \times \sum_{n}(n(\text { predicted })-\mu(\text { predicted }))^{2} / N}{M S D} \\
L C \%=\frac{\left(1-r^{2}\right) \times \sum(n(\text { validation })-\mu(\text { validation }))^{2} / N}{M S D}
\end{gathered}
$$

where, $\mu$ refers to the mean of either predicted values or the validation samples, $b$ is the slope of the least squares regression of measured values as a function of predicted values, $n$ is the sample size of either the predicted values or validation samples, $N$ is the number of pairs of predicted values and validation samples. SB and NU quantify the proportion of the MSD related to the deviance from a 1:1 relationship in the $y$ direction (intercept) and slope, respectively, and LC quantifies the proportion of the MSD related to the scatter of the points about the regression line. The total station data were always considered validation samples for purposes of comparison. When comparing the two LiDAR datasets, the three-scan position LiDAR was considered the validation data.

We examined temporal variability in the vegetation metrics of percent of returns from vegetation, vegetation height, and canopy area at the scale of the plot $(10 \mathrm{~m} \times 10 \mathrm{~m})$ and for plant canopies of individuals aggregated by species. Analysis for the individuals aggregated by species focused on the 
three most abundant species on the plot: Ambrosia deltoidea, Larrea tridentata, and Opuntia engelmannii. We examined the temporal relationships of the LiDAR-derived vegetation metrics with coarse-scale vegetation greenness from Normalized Difference Vegetation Index (NDVI) derived from Moderate Resolution Imaging Spectroradiometer (MODIS) 16-day composite data [36]. As the LiDAR collection time frame spanned over a year, we used 26 composites of 25 MODIS (250 m) NDVI pixels that contained the Desert Laboratory and plot 4 . We also used monthly precipitation data collected from a long-term weather station $<1 \mathrm{~km}$ from plot 4 [4]. The LiDAR-derived vegetation metrics were related to mean MODIS NDVI with a 1-composite (i.e., 16-32 day) lag and to precipitation data using correlation analysis. Although there are substantial differences in the spatial scales at which the LiDAR and MODIS NDVI were collected, the plant communities included in the broader area summarized with MODIS are composed of many of the same shrub and cacti species as the smaller plot in which LiDAR data were acquired.

\section{Result}

\subsection{LiDAR Processing and Measurement Accuracy}

The average total (X, Y, and Z) root mean square error (RMSE) of the LiDAR data post-registration was less than $0.02 \mathrm{~m}$ for all dates and was close to $0.01 \mathrm{~m}$ for a majority of dates (Table 4). Scanning precision was estimated at RMSE of $0.004 \mathrm{~m}$ based on measurements from multiple scans of the reflector spheres.

Examination of LiDAR registration RMSE suggests that a conservative estimate of uncertainty associated with LiDAR height $(\mathrm{Z})$ measurements among the datasets was $<\sim 0.03 \mathrm{~m}$ (i.e., the upper bound of registration RMSE in Table 4). Similarly, uncertainties associated with LiDAR length (X or Y) and area $(\mathrm{X} \times \mathrm{Y})$ measurements can be conservatively estimated at $<\sim 0.02 \mathrm{~m}$ and $<\sim 0.0004 \mathrm{~m}^{2}$ (i.e., $0.02 \mathrm{~m} \times 0.02 \mathrm{~m})$ (Table 4).

LiDAR canopy height and area measurements were strongly related to the survey measurements (Table 3, Figure 3a-e) with $r^{2}$ between 0.80 and 0.99. LiDAR measurements collected from a single scan position and three scan positions were strongly related (Figure $3 \mathrm{c}, \mathrm{f}$ ) with $r^{2}$ of 0.77 and 0.85 for measurements of canopy height and area, respectively. For comparison of most pairs of datasets (Figure 3) the greatest proportion of the MSD was attributed to the scatter of points about the regression line (i.e., LC), as opposed to deviances in the slope or intercept from the 1:1 line (SB or NU, respectively). In general, deviations from the 1:1 line indicated that LiDAR tended to slightly under-predict survey measurements of canopy height and area (Figure 3a-e). The greatest departure in accuracy in terms of scanning from a single position was for the LC, and not the SB or NU components-which indicates overall scatter contributing to a lack of correlation and not a bias in the slope or y-intercept-relative to the presumably more accurate three-scan position LiDAR (Figure 3c,d). Scanning the plot from three positions took approximately three times longer than scanning from a single position.

\subsection{Intra-Annual Precipitation and Satellite-Derived Greenness Variability}

The study area received less than $8 \mathrm{~mm}$ of precipitation from April through June 2011 (Figure 4a). More than $200 \mathrm{~mm}$ of precipitation were recorded from July through September 2011, which is common for the summer North American Monsoon. There was no precipitation in October 2011. Moderate 
precipitation comparable to the start of the monsoon season occurred in November and December 2011. Less than $10 \mathrm{~mm}$ per month were recorded from January 2012 to the end of the study in May 2012.
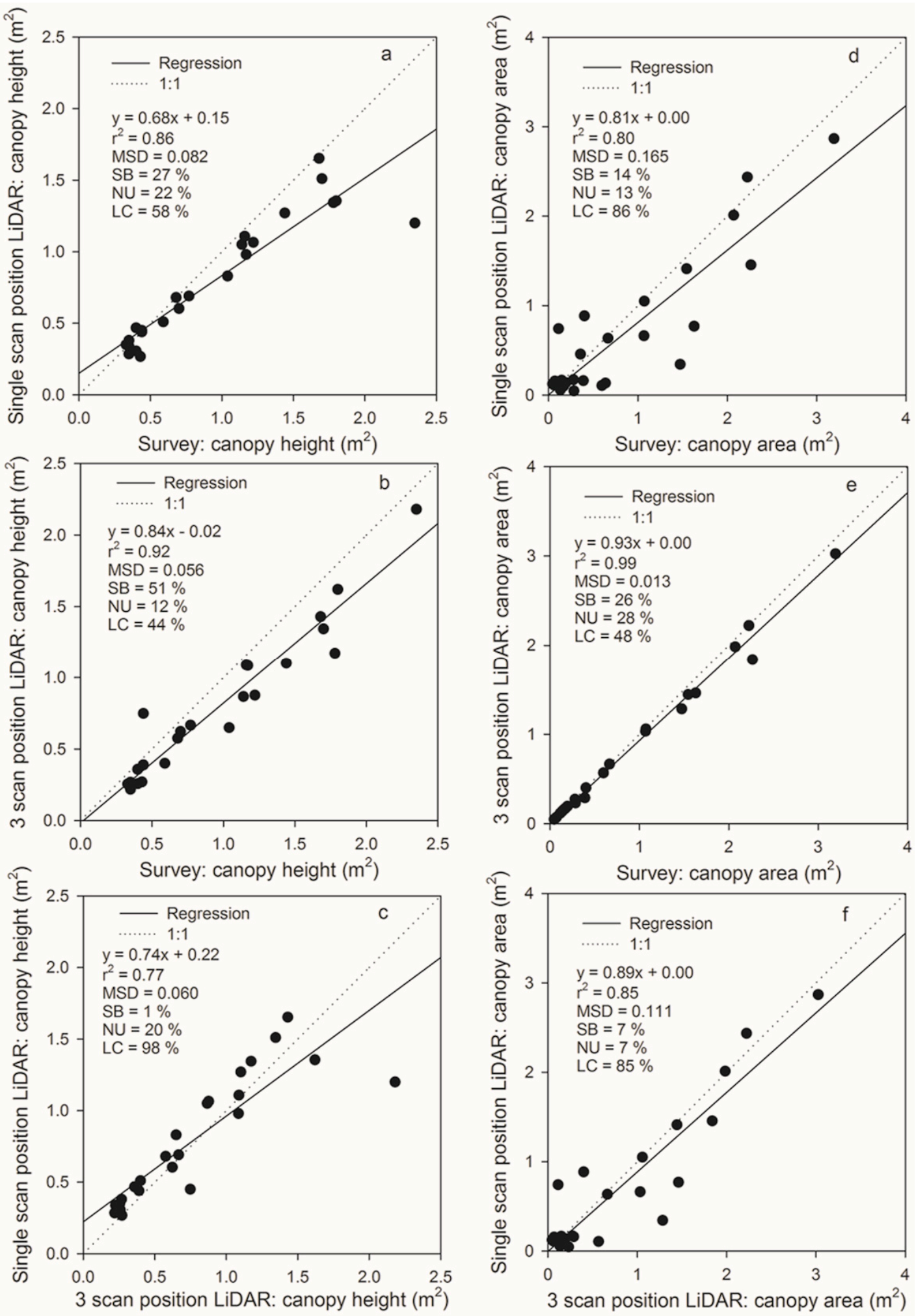

Figure 3. Relationships of LiDAR measurements performed from one scan position or three scan positions and total station survey for canopy height $(\mathbf{a}-\mathbf{c})$ and area $(\mathbf{d}-\mathbf{f})$ of individuals within the study plot. MSD is the mean squared deviation and has components of standard bias (SB), non-unity (NU), and lack of correlation (LC). 

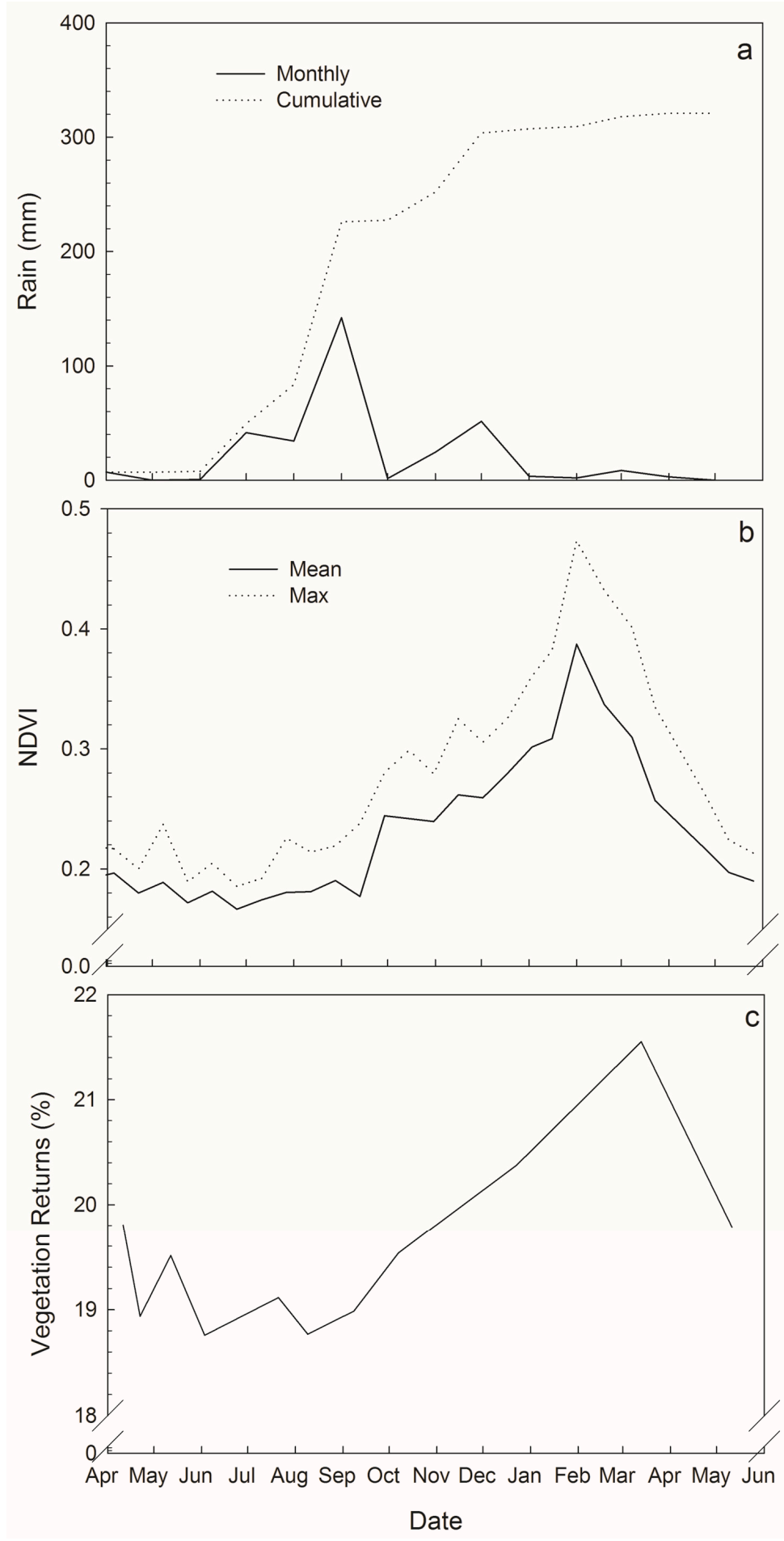

Figure 4. Time series of (a) monthly rainfall at the study area; (b) MODIS 16-day composite satellite-derived vegetation greenness (NDVI) at the study area; (c) percentage of LiDAR returns classified as vegetation (i.e., as opposed to the ground surface) within the study plot.

There was an increase in mean and maximum NDVI of the MODIS pixels containing the Desert Laboratory and plot 4 during the monsoon season indicating an increase in photosynthetic activity and vegetation growth. NDVI peaked at the end of January 2012 (Figure 4b). Precipitation and NDVI were not significantly correlated, though comparison of graphs of NDVI and cumulative precipitation for the 
study period (Figure 4a,b) suggest a possible threshold effect, with NDVI increasing steadily after the September 2011 pulse of precipitation.

\subsection{Plot-Scale Intra-Annual LiDAR Variability}

A consistent positive trend in the percentage of LiDAR returns from vegetation occurred across the plot after August 2011, corresponding to the monsoon season, followed by a subsequent decrease after April 2012 (Figure 4c). Percentage of LiDAR returns from vegetation was positively and linearly correlated with NDVI $(r=0.90, p<0.001)$. LiDAR returns were not, however, significantly correlated with monthly or seasonal rainfall (all $p>0.10$ ).

\subsection{Species-Specific Intra-Annual LiDAR Variability}

The intra-annual variability in LiDAR-derived vegetation metrics for individual plants aggregated by species appeared to be low in many instances (Figure 5). For example, the average percent of vegetation returns within canopies varied by less than $4 \%$ for Larrea tridentata and Opuntia engelmannii (Figure 5a), neither of which produce deciduous foliage. Vegetation height estimates spanned a range of $\sim 0.04 \mathrm{~m}$ for Larrea, Opuntia, and Ambrosia (Figure 5b). Canopy area measurements spanned a range of $\sim 0.1 \mathrm{~m}^{2}$ for the three species (Figure 5c). Despite overall low intra-annual variability of LiDAR-derived metrics at the species-level, vegetation returns for Ambrosia had high temporal variability, showing increasing vegetation returns from September-January (Figure 5a) and indicating its deciduous foliage.

The estimated uncertainty in LiDAR height measurements (described above as $\sim 0.03 \mathrm{~m}$; the upper bound of registration RMSE for $\mathrm{Z}$ in Table 4) appeared comparable in size to the magnitude of variability in LiDAR observations of height throughout the entire time series of data (Figure 5b). Conversely, the estimated uncertainty in LiDAR measurements of canopy area $\left(\sim 0.0004 \mathrm{~m}^{2}\right.$; the product of the upper bound of registration RMSE for X and $\mathrm{Y}$ in Table 4) appeared to be at least an order of magnitude smaller than the magnitude of variability in LiDAR observations of canopy area throughout the entire time series (Figure 5c). Therefore, LiDAR measurements were likely more sensitive to temporal changes in canopy area than changes in canopy height.

Correlation analysis of vegetation metrics at the scale of individuals aggregated by species yielded no significant relationships with precipitation (all $p>0.10$ ). Vegetation returns, canopy height, and canopy area for Ambrosia were all positively related to NDVI determined for the one composite (i.e., $\sim 16-32$ day) lag $\left(\mathrm{r}^{2}=0.53,0.60,0.63\right.$, respectively; Table 5). In contrast, none of the vegetation metrics for Larrea or Opuntia were significantly related to temporal greenness patterns (Table 5).

\section{Discussion}

We examined the sensitivity of terrestrial LiDAR data to intra-annual variability in vegetation structure at a long-term Sonoran Desert monitoring plot. LiDAR estimates of vegetation structure had high precision and we detected intra-annual variability in canopy area with greater confidence compared to height. The ability to resolve and monitor intra-annual vegetation characteristics with LiDAR was dependent on the phenology of the plant species. LiDAR measurements were more sensitive to 
phenological variability exhibited by the drought deciduous shrub Ambrosia deltoidea, compared to the evergreen shrub Larrea tridentata or the cactus Opuntia engelmannii.
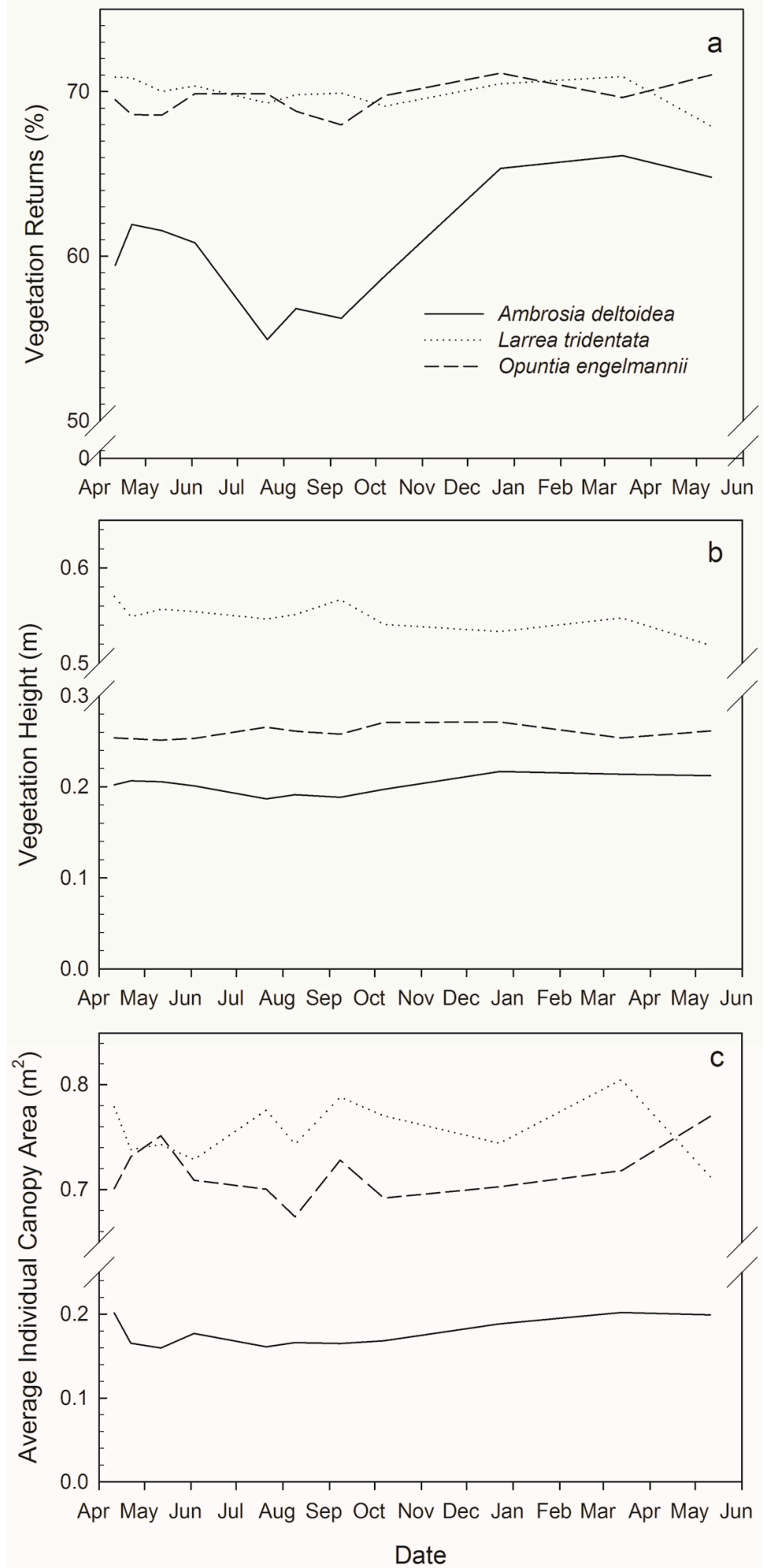

Figure 5. Time series of (a) percentage of LiDAR returns classified as vegetation; (b) vegetation height; (c) canopy area, for individual plant canopies aggregated by species for the three predominant species at the study plot. 
Table 5. Pearson correlation coefficients (p) for times series of LiDAR-derived variables and Normalized Difference Vegetation Index (NDVI) derived from Moderate Resolution Imaging Spectroradiometer (MODIS) 16-day composites (1-composite lag).

\begin{tabular}{cccc}
\hline Species & Vegetation Returns (\%) & Canopy Height $(\mathbf{m})$ & Canopy Area $\left(\mathbf{m}^{\mathbf{2}}\right)$ \\
\hline Ambrosia deltoidea & $\mathbf{0 . 6 3}(\mathbf{0 . 0 4}) *$ & $\mathbf{0 . 6 0}(\mathbf{0 . 0 5})$ & $\mathbf{0 . 5 3}(\mathbf{0 . 0 9})$ \\
Larrea tridentata & $0.24(0.46)$ & $-0.31(0.35)$ & $0.43(0.18)$ \\
Opuntia engelmannii & $0.40(0.22)$ & $0.31(0.35)$ & $-0.11(0.74)$ \\
\hline
\end{tabular}

* bold denotes significant at $p<0.10$.

\subsection{LiDAR Processing and Measurement Accuracy}

LiDAR measurements of canopy metrics were accurate with respect to a census of individual perennial plants using a total station, and our results suggest LiDAR provided a comparable assessment of canopy height and area. Vegetation structure measured from a single scan position produced high correlations with the total station survey measurements, and the increase in correlation was $10 \%-20 \%$ greater when scanning from three positions. Therefore, a LiDAR scan from a single position may be a useful method for rapidly collecting repeat, plot-based measurements in relatively sparse vegetation. Additional scans were more time intensive and may only be needed for very highly detailed vegetation monitoring.

Ground-based LiDAR produced an accurate but more rapid assessment of the individual perennial plants than could typically be performed with the total station census technique. Ground-based LiDAR can provide measurements at higher resolution and potentially lower cost, over smaller extent, relative to LiDAR acquired from a manned aircraft. While the ground-based LiDAR approach is likely better suited to measurement of individual monitoring plots, it could also have operational utility for evaluating the performance of airborne (either piloted airplane or unmanned aerial vehicle) LiDAR, digital photogrammetry, or structure-from-motion approaches that might be used to conduct analogous measurements over greater spatial extent. Ground-based LiDAR therefore might offer an operationally unique and cost-effective approach relative to traditional survey measurements and broader scale airborne or spaceborne remote sensing.

\subsection{Intra-Annual Variability}

LiDAR effectively detected intra-annual changes in vegetation structure within the Sonoran Desert plot. For all vegetation in the plot, vegetation returns steadily increased following post-monsoon precipitation and were related to NDVI, which is consistent with many plants in the Sonoran Desert responding to summer rainfall [25]. Low fluctuations in vegetation returns outside of this very wet summer period could be attributable to a lag or lack of small precipitation events affecting vegetation structure. There was also relatively low intra-annual variability of LiDAR estimates of canopy area and height, which are vegetation structural components that may be more closely associated with non-foliar parts of the plant, and therefore do not change as rapidly.

The intra-annual variability of LiDAR-derived vegetation structure was related to the life history of the individual plant species. For the most abundant species, Ambrosia deltoidea, vegetation returns from LiDAR were highest in the winter and spring, when the shrub typically has leafed-out and has maximum photosynthetic rates [37]. Plant water potentials are typically reduced during the driest months 
of the late spring-early summer, before the onset of the summer monsoon, which usually causes the shed of drought-deciduous leaves. This change in phenology was captured by vegetation returns, which can describe subtle changes in the density of LiDAR returns within the plant canopy, whereas canopy area and height were likely more influenced by slow-changing woody components of the plant. In contrast, Larrea tridentata is evergreen, long-lived, and maintains photosynthesis and leaf turgor at very low water potentials [38]. Opuntia engelmannii, like many succulents, stores water and its cladodes retain turgor under very dry conditions; succulents like Opuntia therefore generally exhibit only modest structural adjustments to increases and decreases in available water [39]. Consequently, the evergreen Larrea and Opuntia both had very low temporal variability in vegetation structure that was within the range of uncertainty in LiDAR measurements and was not significant. In a related manner, vegetation returns from LiDAR for the deciduous shrub Ambrosia, but not the evergreen shrub or cactus, were correlated with NDVI. This is due to the structural changes in Ambrosia leaf density, the phenology of which would have a unique temporal pattern in greenness due to its drought deciduous nature. Conversely, Larrea and Opuntia retained photosynthetically active green tissue throughout the study period. High-resolution LiDAR measurements in this study provided fine-scale estimates of the phenological variables and appeared to be consistent with coarse-scale patterns in MODIS NDVI.

In addition to assessing intra-annual patterns, LiDAR may show utility at measuring vegetation structural changes at annual to decadal scales. Cover of the short-lived shrub Ambrosia deltoidea responds to annual precipitation [40], and there have been several mortality and new recruitment events tracked by the long-term census maps (Tables 1 and 2; Bowers, 2002, 2005). Cover of long-lived Larrea is sensitive to winter precipitation over decadal scales and this response is highly dependent on landform and soil development, whereas cover of cacti has increased over decadal scales in response to warming temperature $[2,40]$. LiDAR can likely be used to track these vegetation structural changes at longer time-scales. However, our results indicate that careful consideration should be made to the time of year or the phenological stage of vegetation before conducting a repeat measurement.

\section{Conclusions}

We determined that ground-based LiDAR is an effective tool to detect intra-annual variability in vegetation structure at a long-term Sonoran Desert monitoring plot dominated by cacti, deciduous and evergreen shrubs. LiDAR measurements of canopy height and area were strongly correlated with $\left(R^{2}>0.80\right)$, and accurate with respect to, measurements conducted during a census of individual perennial plants using a total station. We found a tradeoff between measurement accuracy and time needed for data collection, as LiDAR data collected with a single scan from one side of the plot had $10 \%-20 \%$ lower correlation with the total station census, but could be completed at least three times more quickly than three scan positions. Importantly, we were able to detect significant intra-annual phenological variability with repeat scans over the course of one year from a single scan position. LiDAR significantly detected seasonal variability in canopy height and area with average errors of $0.03 \mathrm{~m}$ and $0.0004 \mathrm{~m}^{2}$, respectively. We detected significant intra-annual variability in the canopy structure of the drought deciduous shrub Ambrosia deltoidea but not other dominant evergreen and succulent species. This suggests that while the utility of LiDAR as a monitoring method in this and other desert ecosystems is high, the ability to resolve intra-annual vegetation characteristics is dependent on 
the plant species assemblage. Future work should evaluate the method for larger samples of plant species assemblages and monitoring plots, and its utility to predict additional plant (e.g., LAI) and ecosystem (e.g., net primary production) characteristics. As many other desert ecosystems share succulent and shrub growth forms with the Desert Laboratory, ground-based LiDAR is likely to be an effective monitoring method in other arid regions.

\section{Acknowledgments}

This research was supported by U.S. Geological Survey Mendenhall Fellowships (Joel Sankey and Seth Munson). Any use of trade, product, or firm names is for descriptive purposes only and does not imply endorsement by the U.S. government.

\section{Author Contributions}

Joel B. Sankey wrote the manuscript and led the data acquisition and analysis. Seth M. Munson helped interpret the results and write the manuscript. Robert $\mathrm{H}$. Webb conceived of the study and helped write the manuscript. Cynthia S.A. Wallace helped with data acquisition. Cesar M. Duran analyzed the data.

\section{Conflicts of Interest}

The authors declare no conflict of interest.

\section{References}

1. Goldberg, D.E.; Turner, R.M. Vegetation change and plant demography in permanent plots in the Sonoran Desert. Ecology 1986, 67, 695-712.

2. Munson, S.M.; Webb, R.H.; Belnap, J.; Hubbard, J.A.; Swann, D.E.; Rutman, S. Forecasting climate change impacts to plant community composition in the Sonoran Desert region. Glob. Chang. Biol. 2012, 18, 1083-1095.

3. Webb, R.H.; DeFalco, L.A.; Esque, T.C.; Medica, P.A. A review of selected long-term ecological studies of the Mojave Desert. In Mojave Desert: Ecosystem Processes and Sustainability; Webb, R.H., Fenstermaker, L.F., Heaton, J.S., Hughson, D.L., McDonald, E.V., Miller, D.M., Eds.; University of Nevada Press: Reno, NV, USA, 2009; pp. 429-456.

4. Webb, R.H.; Turner, R.M. A debt to the past: Continuing long-term and current research at the Desert Laboratory in Tucson. Desert Plants 2011, 26, 3-18.

5. Canfield, R.H. Application of the line interception methods in sampling range vegetation. J. For. 1941, 39, 388-394.

6. Daubenmire, R. A canopy-coverage method of vegetational analysis. Northwest Sci. 1941, 33, $43-64$.

7. Munson, S.M.; Webb, R.H.; Hubbard, J.A. A comparison of methods to assess long-term changes in Sonoran Desert vegetation. J. Arid Environ. 2011, 75, 1228-1231.

8. The Desert Laboratory Repeat Photography Collection-An Invaluable Archive Documenting Landscape Change. U.S. Geological Survey Fact Sheet 2007-3046, 2007. Available online: http://pubs.usgs.gov/fs/2007/3046/ (accessed on 9 December 2014). 
9. Eitel, J.U.H.; Vierling, L.A.; Long, D.S. Simultaneous measurements of plant structure and chlorophyll content in broadleaf saplings with a terrestrial laser scanner. Remote Sens. Environ. 2010, 114, 2229-2237.

10. Magney, T.S.; Eusden, S.A.; Eitel, J.U.H.; Logan, B.A.; Jiang, J.; Vierling, L.A. Assessing leaf photoprotective mechanisms using terrestrial LiDAR: Towards mapping canopy photosynthetic performance in three dimensions. New Phytol. 2013, 201, 344-356.

11. Ku, N.W.; Popescu, S.C.; Ansley, R.J.; Perotto-Baldivieso, H.L.; Filippi, A.M. Assessment of available rangeland woody plant biomass with a terrestrial LiDAR system. Photogram. Eng. Remote Sens. 2012, 78, 349-361.

12. Mitchell, J.J.; Glen, N.F.; Sankey, T.T.; Derryberry, D.R.; Anderson, M.O.; Hruska, R.C. Small-footprint LiDAR estimations of sagebrush canopy characteristics. Photogram. Eng. Remote Sens. 2011, 77, 521-530.

13. Popescu, S.C.; Wynne, R.H.; Nelson, R.F. Estimating plot-level tree heights with LiDAR: Local filtering with a canopy-height based variable window size. Comput. Electron. Agric. 2002, 37, 71-95.

14. Popescu, S.C.; Wynne, R.H. Seeing the trees in the forest: Using LiDAR and multispectral data fusion with local filtering and variable window size for estimating tree height. Photogram. Eng. Remote Sens. 2004, 70, 589-604.

15. Zhao, K.; Popescu, S.; Meng, X.; Pang, Y.; Agca, M. Characterizing forest canopy structure with LiDAR composite metrics and machine learning. Remote Sens. Environ. 2011, 115, 1978-1996.

16. Hudak, A.T.; Strand, E.K.; Vierling, L.V.; Byrne, J.; Eitel, J.U.H.; Martinuzzi, S.; Falkowski, M.J. Quantifying aboveground forest carbon pools and fluxes from repeat LiDAR surveys. Remote Sens. Environ. 2012, 123, 25-40.

17. Sankey, T.T.; Shrestha, R.; Sankey, J.B.; Hardegree, S.; Strand, E. LiDAR-derived estimate and uncertainty of carbon sink in successional phases of woody encroachment. J. Geophys. Res.-Biogeosci. 2013, 118, 1144-1155.

18. Riaño, D.; Valladares, F.; Condés, S.; Chuvieco, E. Estimation of leaf area index and covered ground from airborne laser scanner (LiDAR) in two contrasting forests. Agric. For. Meteorol. 2004, 124, 269-275.

19. Arno, J.; Escola, A.; Valles, J.; Llorens, J.; Sanz, R.; Msip, J.; Palacin, J.; Rosell-Polo, J.R. Leaf area index estimation in vineyards using a ground-based LiDAR scanner. Precis. Agric. 2013, 14, 290-306.

20. Zhao, F.; Yang, X.; Schull, M.A.; Roman-Colon, M.O.; Yao, Tian, Wang, Z. Measuring effective lead area index, foliage profile, and stand height in New England forests using a fullwaveform ground-based LiDAR. Remote Sens. Environ. 2011, 115, 2954-2964.

21. Sankey, J.B.; Ravi, S.; Wallace, C.S.A.; Webb, R.H.; Huxman, T.E. Quantifying soil surface change in degraded drylands: Shrub encroachment and effects of fire and vegetation removal in a desert grassland. J. Geophys. Res. 2012, 117, doi:10.1029/2012JG002002.

22. Sankey, J.B.; Law, D.J.; Breshears, D.D.; Munson, S.M.; Webb, R.H. Employing LiDAR to detail vegetation canopy architecture for prediction of aeolian transport. Geophys. Res. Lett. 2013, 40, $1724-1728$. 
23. Eitel, J.U.H.; Vierling, L.A.; Magney, T.S. A lightweight, low cost autonomously operating terrestrial laser scanner for quantifying and monitoring ecosystem structural dynamics. Agric. For. Meteorol. 2013, 180, 86-96.

24. Higgins, R.W.; Yao, Y.; Wang, X.L. Influence of the North American Monsoon system on the U.S. summer precipitation regime. J. Clim. 1997, 10, 2600-2622.

25. Bowers, J.E. Regeneration of triangle-leaf bursage (Ambrosia deltoidea: Asteraceae): Germination behaviour and persistent seed bank. Southwest. Nat. 2002, 47, 449-513.

26. Bowers, J.E. Effects of drought on shrub survival and longevity in the northern Sonoran Desert. J. Torrey Bot. Soc. 2005, 132, 421-431.

27. Bowers, J.E. Has climatic warming altered spring flowering date of Sonoran desert shrubs? Southwest. Nat. 2007, 52, 347-355.

28. Bowers, J.E. A debt to the future: Achievements of the Desert Laboratory, Tumamoc Hill, Tucson, Arizona. Desert Plants 2010, 26, 25-39.

29. One Hundred and Six Years of Population and Community Dynamics of Sonoran Desert Laboratory Perennials. Available online: http://pubs.er.usgs.gov/publication/70038720 (accessed on 18 December 2014).

30. Rodriguez-Buritica, S.; Raichle, H.; Webb, R.H.; Turner, R.M.; Venable, L. One hundred and six years of population and community dynamics of Sonoran Desert Laboratory perennials. Ecol. Arch. 2013, 94, 976-976.

31. Turner, R.M.; Brown, D.E. Sonoran desertscrub. Biotic Communities of the American Southwest-United States and Mexico. Desert Plants 1982, 4, 181-221.

32. InnovMetric Software. PolyWorks V10.1 Beginner's Guide; InnovMetric Software Inc.: Quebec, QC, Canada, 2008; p.118.

33. Evans, J.S.; Hudak, A.T.; Faux, R.; Smith, A.M.S. Discrete return LiDAR in natural resources: Recommendations for project planning, data processing, and deliverables. Remote Sens. 2009, 1, 776-794.

34. Streutker, D.E.; Glenn, N.F. LiDAR measurement of sagebrush steppe vegetation heights. Remote Sens. Environ. 2006, 102, 135-145.

35. Gauch, H.G., Jr.; Hwang, J.T.G.; Fick, G.W. Model evaluation by comparison of model-based predictions and measured values. Agron. J. 2003, 95, 1442-1446.

36. Solano, R.; Didan, K.; Jacobson, A.; Huete, A. MODIS Vegetation Indices (MOD13) C5-User's Guide; The University of Arizona: Tucson, AZ, USA, 2010; p. 38.

37. Szarek, S.R.; Woodhouse, R.M. Ecophysiological studies of Sonoran Desert Plants. Oecologia 1977, 28, 365-375.

38. Meinzer, F.C.; Rundel, P.W.; Sharifi, M.R.; Nilsen, E.T. Turgor and osmotic relations of the desert shrub Larrea tridentate. Plant Cell Environ. 1986, 9, 467-475.

39. Spalding, E.S. Mechanical adjustment of the saguaro (Cereus giganteus) to varying quantities of stored water. Bull. Torrey Bot. Club 1905, 32, 57-68.

40. Munson, S.M. Plant responses, climate pivot points, and trade-offs in water-limited ecosystems. Ecosphere 2013, 4, doi:10.1890/ES13-00132.1.

(C) 2014 by the authors; licensee MDPI, Basel, Switzerland. This article is an open access article distributed under the terms and conditions of the Creative Commons Attribution license (http://creativecommons.org/licenses/by/4.0/). 